Rev. Latinoam. Psicopat. Fund., VII, 2, 7-10

Editorial

\title{
Revistas científicas internacionais em países de baixa e média renda
}

O Departamento de Saúde Mental e Abuso de Substâncias da Organização Mundial da Saúde - OMS organizou um encontro sobre Pesquisa em Saúde Mental em Países em Desenvolvimento: o papel das revistas científicas, em Genebra, nos dias 20 e 21 de novembro de 2003, do qual participaram 25 editores representando revistas científicas que publicam pesquisa em saúde mental. Muitos outros editores contribuíram fornecendo dados, elaborando e revisando esse material.

A revista Psiquiatria Hoje, da Associação Brasileira de Psiquiatria, publicou, no número 1, de 2004 (ano XXVI), um artigo do prof. dr. Jair Mari contendo um detalhado relatório dessa reunião, junto com a lista dos participantes e a de idéias que lá surgiram.

Segundo o prof. Mari,

Precisa-se de pesquisa para que se trate a enorme quantidade de necessidades não-atendidas em saúde mental em países de baixa e média renda (B\&MR). Revistas científicas desempenham um papel importante na produção e na disseminação de pesquisa. Contudo, no momento, somente uma minúscula proporção das pesquisas publicadas em revistas de psiquiatria e saúde mental de acesso amplo provém ou diz respeito a esses países. Porém, mais de 85\% da população mundial vive nos 153 países classificados como de baixa ou média renda, conforme critérios do Banco Mundial. Até mais preocupante é a observação de que a distância existente entre esses e os países de alta renda pode estar aumentando em termos de seu número de publicações. $O$ encontro teve por objetivo buscar formas de resolver essa situação insatisfatória.

O reconhecimento de que há numerosos obstáculos não só à produção de pesquisas como de sua publicação em revistas internacionais 
por parte dos especialistas dos países de B\&MR não deveria servir de argumento para um certo conformismo imobilista que se manifesta com certa freqüência. Como observa o prof. Mari, precisamos encarar o desafio de diminuir as barreiras à publicação de pesquisa em saúde mental desenvolvida por investigadores que trabalham em países de B\&MR.

Para que isso ocorra, é necessário um trabalho de gestão de pesquisa e autoria promovendo um ambiente produtivo. Assim, por exemplo, não basta haver uma única revista internacional em saúde mental em cada país de B\&MR. É necessário, antes disso, que se crie uma rede de publicações acompanhando o aumento do número de artigos produzidos nesses países. Um país de B\&MR que tenha um número significativo de ótimas revistas científicas nacionais é capaz de gerar um pequeno, mas consistente, número de artigos internacionais. Como diz o prof. Mari, tempo, conhecimento, recursos e comprometimento são necessários para a publicação de estudos relevantes desses países. É necessário, porém, que esses mesmos países criem estruturas produtivas de pesquisas, bem como um mercado consumidor desses artigos. Em outras palavras, não basta ter autores de artigos publicados em revistas internacionais. É necessário que os leitores dos países de B\&MR tenham acesso fácil a periódicos internacionais para que seu trabalho e sua vida se beneficiem dessa situação. Isso, por exemplo, não ocorre no Brasil. $\mathrm{O}$ acesso às revistas internacionais promovido pela Capes, ainda que competente, é seletivo e elitista. Profissionais de saúde mental, por exemplo, não têm direito a acessar o portal da Capes que só oferece essa oportunidade a instituições universitárias e seus filiados - professores e estudantes. Sabemos perfeitamente que a Capes é uma agência voltada para o aperfeiçoamento do pessoal do ensino superior. Entretanto, construir uma capacidade produtiva de conhecimento auto-sustentável passa pelo reconhecimento nacional de que essa produção é relevante para qualquer cidadão e que qualquer cidadão pode ter acesso às informações existentes e disponíveis. Se a Capes investe milhões de reais para construir um portal com revistas científicas, por que não coloca esse serviço à disposição da população em geral? Enquanto isso não ocorrer nos países de B\&MR, a produção científica será um benefício voltado para a concentração de renda e a existência de estilos de vida muito díspares.

Como observa o prof. Mari, um dos principais empecilhos ao acesso à pesquisa em saúde mental de países de B\&MR é a falta de visibilidade de revistas publicadas nesses países. Sua maioria não é indexada em bancos de dados internacionais e, com freqüência, não está disponível fora de seu país ou região de origem. De fato, essas revistas, muitas vezes publicadas sob condições extenuantes, não conseguem se inscrever no âmbito internacional por diversos motivos que precisam ser melhor investigados. Muitas vezes, as línguas desses países são um obstáculo intransponível para as revistas adquirirem um status internacio- 
nal. Por outro lado, se elas são editadas em inglês, perdem uma enorme quantidade de leitores que desconhecem essa língua. Além disso, a redação de artigos em língua estrangeira elimina as sutilezas do pensamento e da escrita produzindo uma padronização da linguagem e a conseqüente banalização dos trabalhos, que se tornam monotonamente repetitivos e insignificantes, mas de padrão internacional. Revistas científicas de países de B\&MR devem ser, portanto, “multilingüistas”, ou seja, devem publicar artigos em diversas línguas, com predominância daquela onde a revista mais circula. Além disso, as revisões dos artigos por pares deve visar um trabalho construtivo de autoria e não o corte puro e simples do trabalho que não atende os padrões de exigência. Em outras palavras, as revistas científicas de países de B\&MR não devem ser feitas para publicar apenas artigos internacionais. Devem servir de estímulo a autores iniciantes e jovens que ainda não conhecem direito os meandros da publicação. Uma revista científica que publica artigos significantes e que possui uma boa circulação nacional, se estiver articulada a estruturas produtivas de pesquisa, rapidamente gera autoria. Com esses elementos básicos, autores, leitores e critérios editoriais que produzem um desenvolvimento paulatino e seguro da autoria, a revista científica nacional pode almejar o status de publicação internacional publicando artigos em inglês, única língua considerada internacional, e se fazendo presente, de forma segura e paulatina, em bibliotecas de universidades estrangeiras.

A Revista Latinoamericana de Psicopatologia Fundamental possui um evidente projeto internacional. Entretanto, ainda não alcançou esse status. Para isso, alguns decisivos passos já foram dados e ela já alcançou uma posição nacional de destaque. Além disso, o número de autores estrangeiros que a Revista publica vem aumentando consistentemente, e seu índice de impacto vem aumentando na medida em que artigos aí publicados são citados em outros trabalhos. As recentes modificações editoriais introduzidas visam, também, a publicação de trabalhos relevantes para a psiquiatria, para a saúde mental, para a história e, principalmente, para a melhoria do nível do trabalho em saúde mental.

A Revista vai, assim, se tornando cada vez mais conhecida e respeitada e é esse trabalho que a levará a um reconhecimento internacional. Não podemos, entretanto, ter pressa e querermos que as coisas aconteçam do dia para a noite. Há dez anos, a psicopatologia fundamental era praticamente desconhecida, a não ser no âmbito universitário francês.

O I Congresso Internacional de Psicopatologia Fundamental e o VII Congresso Brasileiro de Psicopatologia Fundamental revelam o reconhecimento da comunidade científica pelo trabalho que estamos realizando. Além disso, é crescente o ritmo e a intensidade da produção escrita de psicopatologia fundamental.

A Revista já tem um alcance internacional que vem se consolidando e é, hoje, um periódico dos mais promissores em saúde mental. 
Sustentada pela Associação Universitária de Pesquisa em Psicopatologia Fundamental, reunindo cerca de 45 professores-doutores de universidades da América Latina e da Europa, a Revista é órgão oficial de sólida estrutura produtiva de pesquisa. Sua política editorial, estimulando e acolhendo artigos de autores de diferentes posições teórico-metodológicas, é francamente pluralista e não pretende a defesa de pontos de vista paroquiais ou considerados hegemônicos por qualquer establishment. Por outro lado, seus limites são bastante claros: os artigos aí publicados não se opõem à natureza subjetiva do pathos psíquico.

Devemos, portanto, prosseguir o trabalho que estamos realizando, de forma dedicada e concentrada, visando manter e aprimorar o padrão científico já alcançado. Só assim, com obstinada persistência, construiremos uma base sólida de pesquisa e produção científica em psicopatologia fundamental e o reconhecimento internacional virá a seu tempo, como já vem ocorrendo.

Quando esta edição da Revista estava pronta, recebemos o seguinte e-mail:

"Estimado Dr. Manoel Tosta Berlinck:

Tenemos el placer de comunicarles que la Revista Latinoamericana de Psicopatologia Fundamental ha sido incluida en PSICODOC, base de datos bibliográfica de Psicología en español, http://psicodoc.copmadrid.org, editada por el Colegio Oficial de Psicólogos de Madrid y patrocinada por la UNESCO con los auspicios de la Internacional Union of Psychological Science, IUPsyS .

Adjuntamos una ficha para que una vez cumplimentada nos la remitan, con el fin de incorporar correctamente sus datos en el catálogo de publicaciones periódicas, que se publicará en la web este año.

Nuestro deseo es contribuir a la mejora de la calidad de las publicaciones científicas y profesionales en Psicología.”

Consuelo Gallardo

Coordinadora PSICODOC/ Responsable Biblioteca y Documentación

Colegio Oficial de Psicólogos de Madrid

Cuesta de San Vicente N 4, 6 ${ }^{\mathrm{a}}$ pl. E- 28008 Madrid

Tf: 34-91541 9999 Ext. 615 / Fax: 34-91559 0303

http://psicodoc.idbaratz.com

http://www.copmadrid.org

htt://www.cop.es 